evaporated until it is sufficiently concentrated; in this state it will easily restore the blue color of reddened paper, and will give abundant precipitates with the chloruret of platina and the perchloric acid, as would a concentrated solution of the carbonate of potash. The use of these re-agents would be accompanied even with a well-marked effervescence.

I should not recommend pushing the experiment further, and treating, for example, the mass already exhausted by alcohol with water or acetic acid, be. cause, while acknowledging that by their means we might dissolve a certain quantity of potash, which had been used as a poison, it is certain that we should also dissolve a considerable quantity of the salts of potash naturally contained in the animal liquids and in food, so that we should run the risk of committing serious errors, in attributing to potash taken as a poison, re-actions due to the salts of potash naturally in the system. It were a hundred times better not to seek to separate the entire of the potash which has acted as a poison.-Journ. de Chimie Médicale.

\section{CASE OF MONSTROSITY.}

\section{TO THE EDITORS OF THE PROVINCIAL MEDICAL} JOURNAL.

Gentlemen, - If you think the following case worthy of record in your valuable Journal, I shall be gratified by its insertion.

I am, Gentlemen,

Your obedient servant, W. B. SANDERSON.

Ipswich, June 27, 1842.

November 29,1841 . I was called to Mrs. L., aged thirty-six, who has been married fourteen years, and was in labour of her first child. I found the os uteri well dilated, and the membranes protruding largely, through the volume of which I was unable to ascertain the presentation. I, therefore, ruptured them, and a large quantity of the liquor amnii escaped; when, on several further examination, with much puzzling and difficulty, I diagnosed an acephalous fœtus, by feeling the craggy edges of the base of the cranium, surrounding a soft, pulpy mass, which occupied the site of the brain. This proved a correct opinion on delivery, when $I$ received a complete monstrosity, presenting the extraordinary aspect of two distinct and perfect faces, united to one cranial base, and possessing four perfect and lucid eyes, two noses, two mouths, each divided by a septum, with a separate tongue and gums, and two chins; the rest of the body normal, well formed, and of good average size; one ear only on each side of the cranial base.

On viewing the posterior part of the trunk, I obsèrve (for I possess the curiosity) the spinal column deficient in the spinous processes of the vertebræ, the chord and its membranes exposed superficially, and the transverse processes widely separated throughout their whole length, until they unite at the sacrum.

On opening the thorax and abdomen, $I$ found their contents perfectly normal. I did not trace the faucial, œsophageal, or bronchial formations, being unwilling to disfigure my preparation so much as such an in. vestigation would involve.
I may add, it is a female child, and the mother felt its powerful movement a short time prior to delivery. Respiration never occurred.

\section{ON SPONTANEOUS FRACTURE OF THE THIGH-BONE.}

By Jonathan Toogood, Esq.

Senior Surgeon to the Bridgwater Infirmary.

In the course of my practice, two cases have occurred in which the thigh has been fractured without any external violence. The first was that of a man who had for many years been in a weak, nervous, and half paralytic state. In attempting to turn in bed, the bone broke. The case was considered an extraordinary one ; it was treated in the usual way, and united after a considerable time, and he lived many years after. The next case was that of James Pople's wife, of Bawdrip, aged fifty-five, who had been long in an infirm state of health, which terminated ultimately in paralysis of the lower extremities. She had suffered very severe pain in her right thigh for some months, which was considered by those about her to be rheumatic; and being a poor woman without friends, little was done for her relief. One evening, on being lifted up in the bed, the bone suddenly snapped; she was aware of it immediately, and cried out that her thigh was broken, but no one believed her, and she lay all that night in dreadful agony, but when, on the following morning, her neighbours saw the limb almost doubled by the viulent spasmodic action of the muscles which drew the ends of the bones forcibly against each other, I was requested to see her. Her condition was indeed truly deplorable, and the grating of the bones against each other was distinctly heard.

The limb was placed in splints, and united after a longer period than usual. I mentioned this case to Sir:Astley Cooper, who considered it to be cancer of the bone, and directed my attention to the state of the breasts, in both of which I discovered on examination several hard, knotty tumors, of a carcinomatous character.

The following interesting account of a similar accident will be found in the life of Archbishop Secker :-

"About a year and a half before he died, after a fit of the gout, he was attacked with a pain in the arm, near the shoulder, which, having continued about a twelvemonth, a similar pain seized the upper and outer part of the opposite thigh, and the arm soon became easier. This was much more grievous than the former, as it quickly disabled him from walking, and kept him in almost continual torment except when he was in a reclined position. During this time he had two or three fits of the gout, but neither the gout nor medicines alleviated these pains, which, with the want of exercise, brought him into a general bad habit of body.

On Saturday, the 30th of July, 1768, he was seized, as he sat at dinner with a sickness at his stomach. He recovered himself before night, but the next evening, whilst his physicians were attending, and his servants raising him on his couch, he suddenly cried out that his thigh-bone was broken. The shock was so violent that the servants perceived the couch to shake under him, and the pain so acute and unexpected, 